\title{
Insights Into Fire-based Soil Temperature and Moisture Changes From a Long-term Data Set in Alaska
}

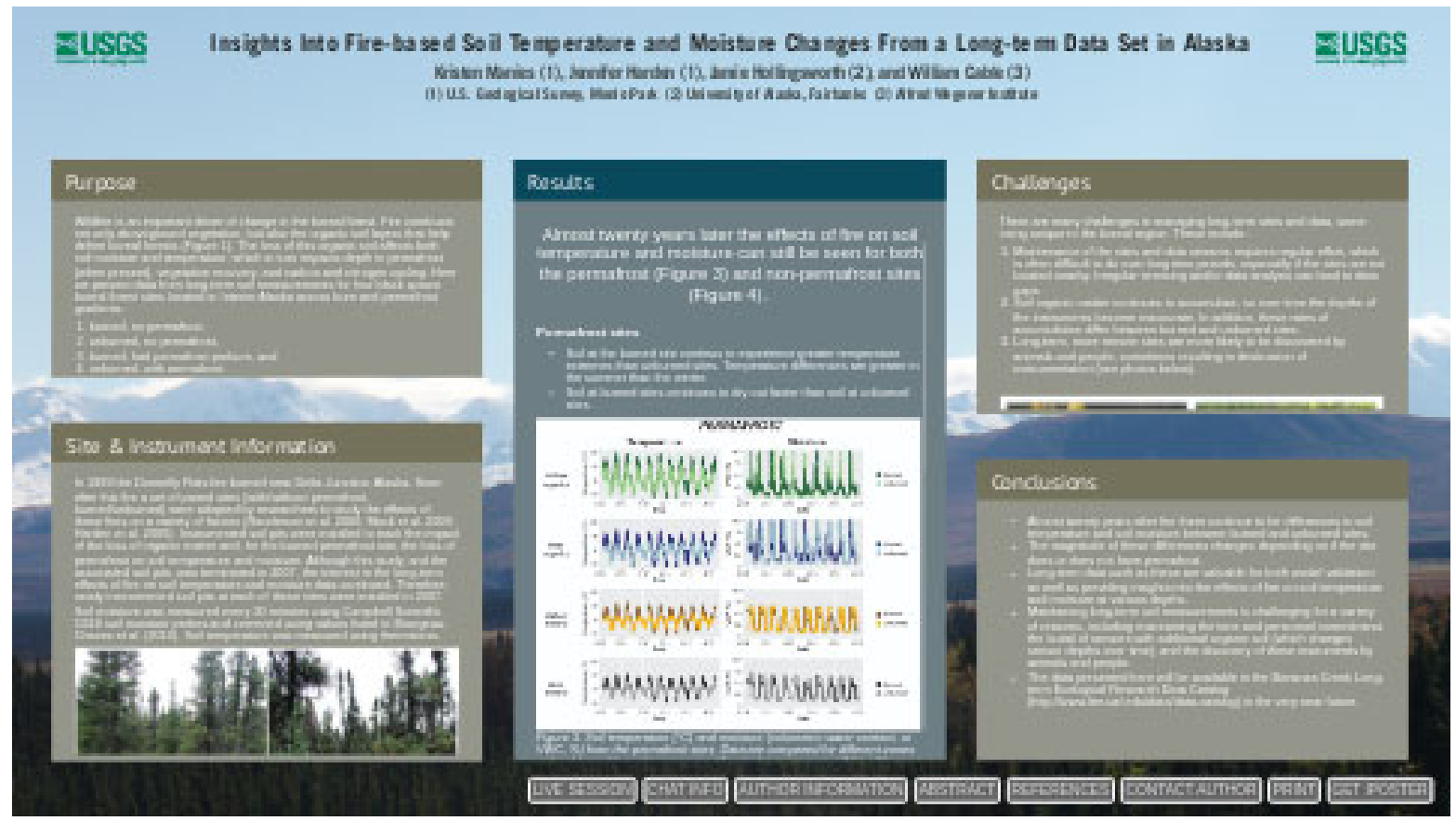

Kristen Manies (1), Jennifer Harden (1), Jamie Hollingsworth (2), and William Cable (3)

(1) U.S. Geological Survey, Menlo Park (2) University of Alaska, Fairbanks (3) Alfred Wegener Institute
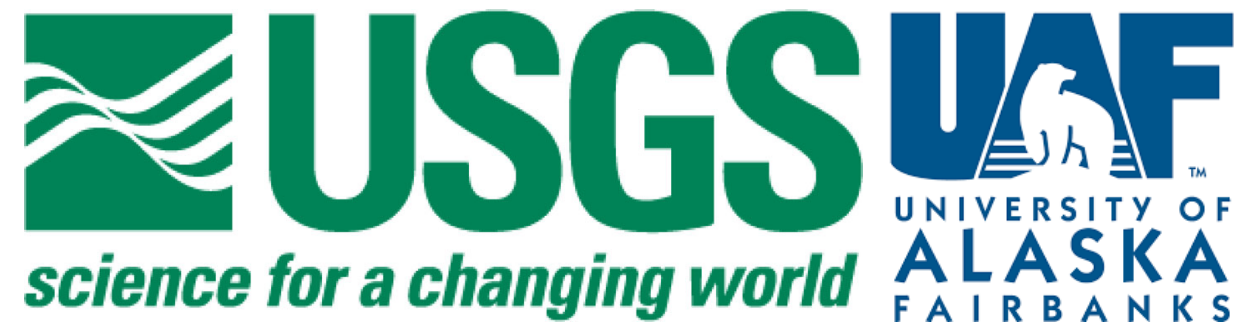

UNIVESITY OF ALASKA

FAIRBANKS

PRESENTED AT:

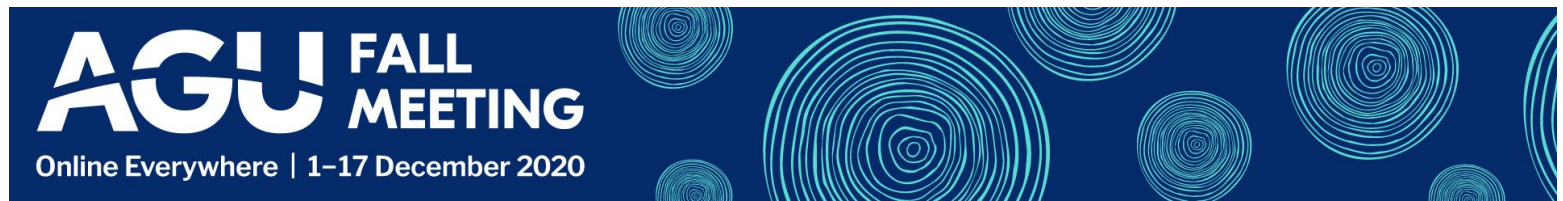




\section{PURPOSE}

Wildfire is an important driver of change in the boreal forest. Fire combusts not only aboveground vegetation, but also the organic soil layers that help define boreal forests (Figure 1). The loss of this organic soil affects both soil moisture and temperature, which in turn impacts depth to permafrost (when present), vegetative recovery, and carbon and nitrogen cycling. Here we present data from long-term soil measurements for four black spruce boreal forest sites located in Interior Alaska across burn and permafrost gradients:

1. burned, no permafrost,

2. unburned, no permafrost,

3. burned, had permafrost preburn, and

4. unburned, with permafrost.

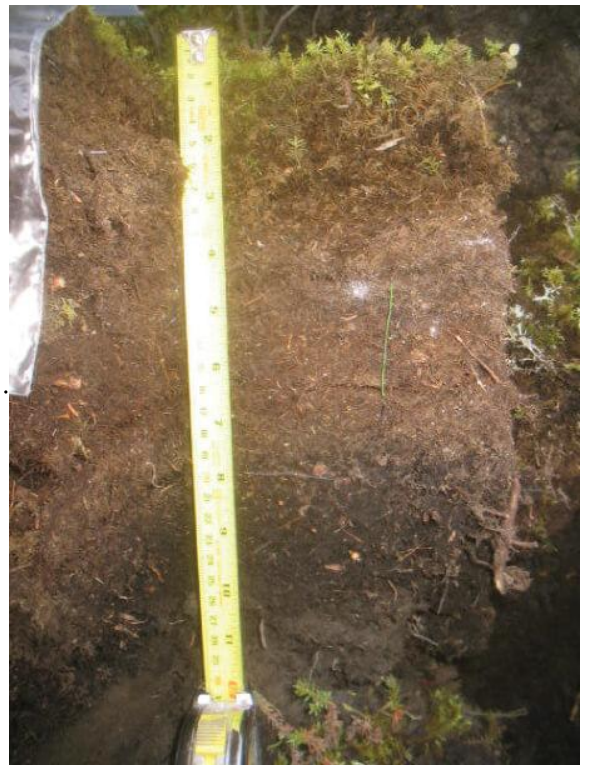

Figure 1. An example of the thick organic soil layers that can be found above the mineral soil surface in boreal forests. This soil was sampled from a moderately drained site with permafrost. On average modelately drained sites have $\sim 30 \mathrm{~cm}$ of organic soil (Manies 2020). Sites without permafrost have thinner organic soil layers $(\sim 6.5 \mathrm{~cm})$. Bulk density, volumetric water content, as well as carbon and nitrogen concentration change with depth for these soil layers (Manies, 2020). 


\section{SITE \& INSTRUMENT INFORMATION}

In 1999 the Donnelly Flats fire burned near Delta Junction, Alaska. Soon after this fire a set of paired sites (with/without permafrost, burned/unburned) were adopted by researchers to study the effects of these fires on a variety of factors (Randerson et al. 2006; Mack et al. 2008; Harden et al. 2006). Instrumented soil pits were installed to track the impact of the loss of organic matter and, for the burned permafrost site, the loss of permafrost on soil temperature and moisture. Although this study, and the associated soil pits, was terminated in 2007 , the interest in the long-term effects of fire on soil temperature and moisture data continued. Therefore, newly instrumented soil pits at each of these sites were installed in 2007. Soil moisture was measured every 30 minutes using Campbell Scientific C616 soil moisture probes and corrected using values listed in Bourgeau-Chavez et al. (2010). Soil temperature was measured using thermistors.
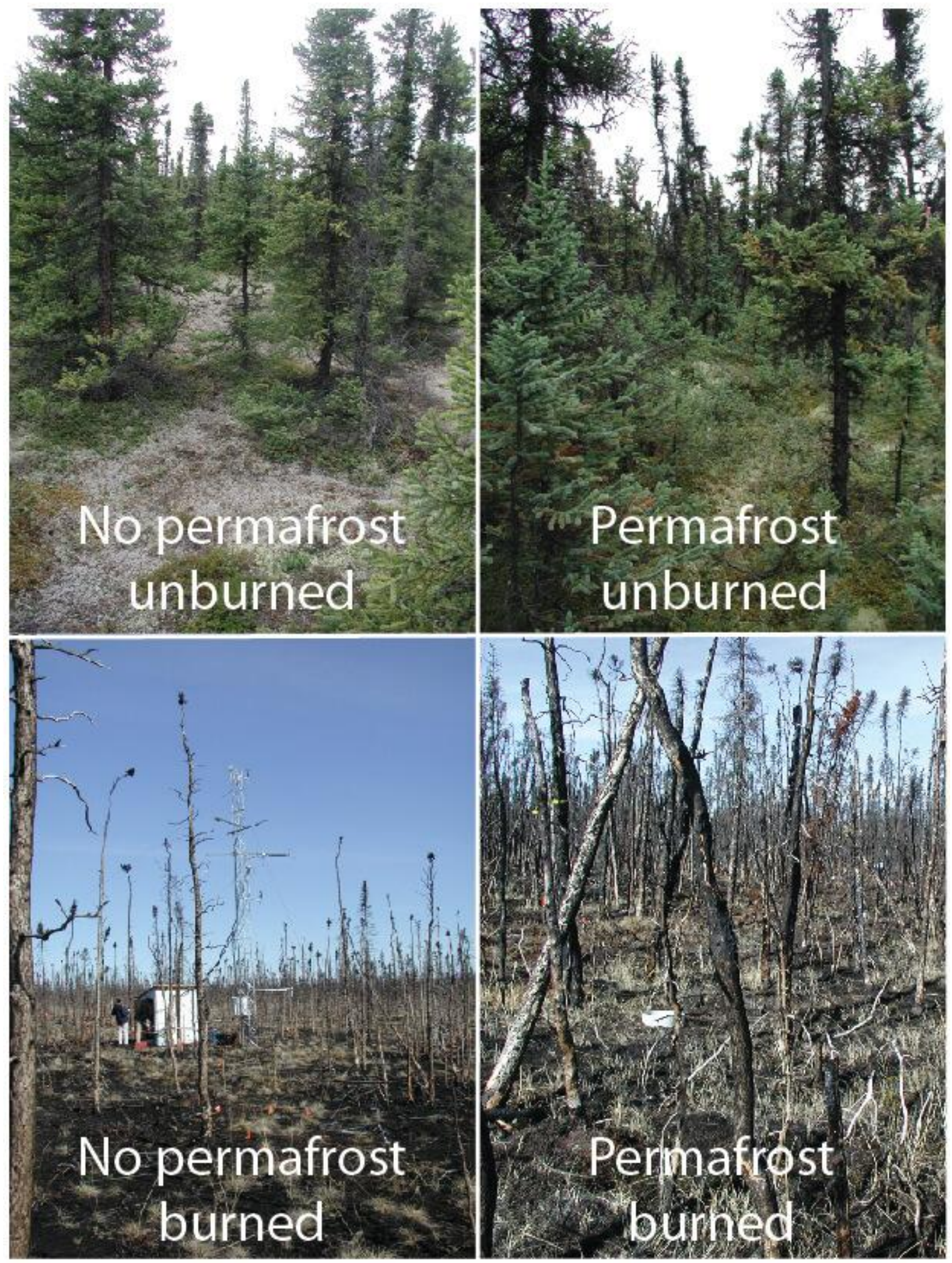
Figure 2. Site photos show that the unburned site without permafrost had lower tree density and more lichen cover than the site with permafrost. Burned sites experienced similar burn severity. 


\section{RESULTS}

Almost twenty years later the effects of fire on soil temperature and moisture can still be seen for both the permafrost (Figure 3) and non-permafrost sites (Figure 4).

\section{Permafrost sites}

- Soil at the burned site continus to experience greater temperature extremes than unburned sites. Temperature differences are greater in the summer than the winter.

- Soil at burned sites continues to dry out faster than soil at unburned sites

\section{PERMAFROST}

Temperature
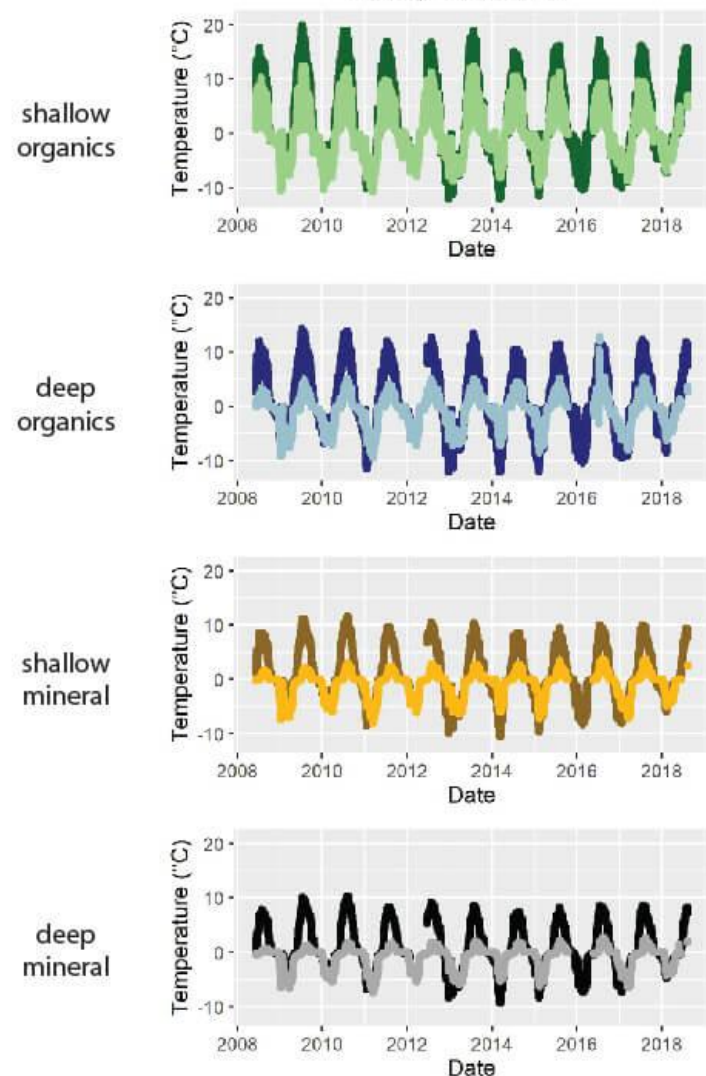
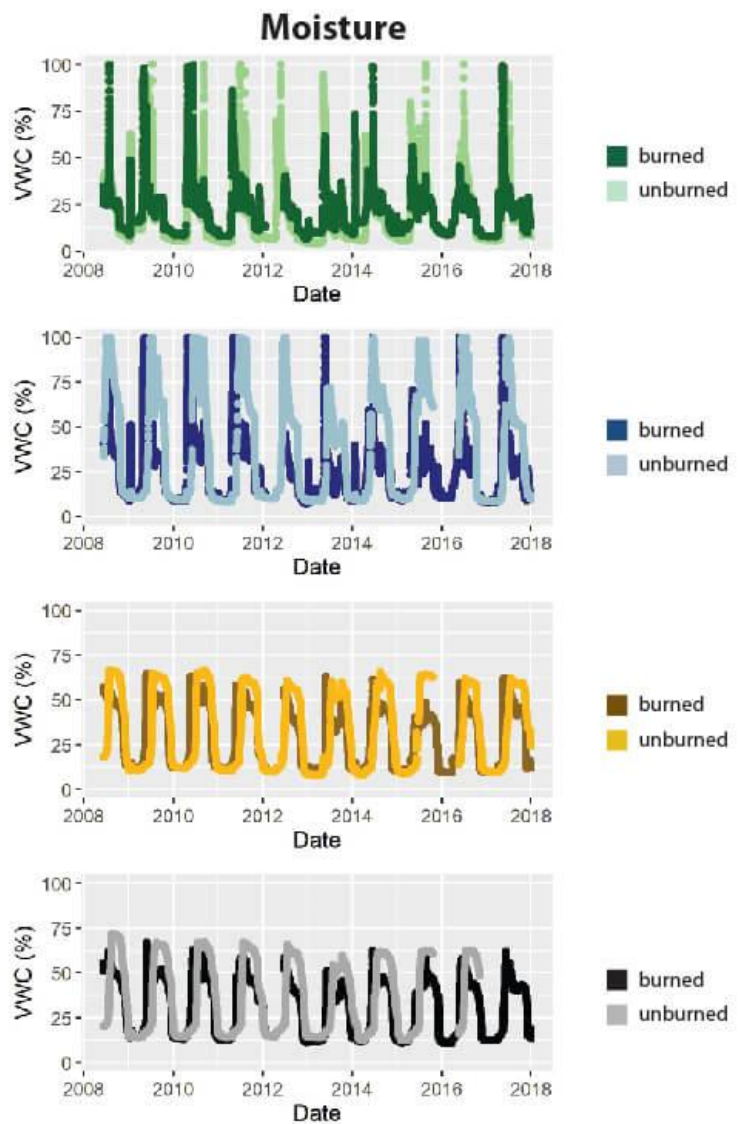

Figure 3. Soil temperature $\left({ }^{\circ} \mathrm{C}\right)$ and moisture (volumetric water content, or VWC, \%) from the permafrost sites Data are compared for different zones within this profile: surface organics (4 cm), deeper organics (11 vs $15 \mathrm{~cm}$ for burned versus unburned sites, respectively), shallow mineral soil $(25 \mathrm{~cm})$, and deeper mineral soil (38 vs $40 \mathrm{~cm}$ for burned versus unburned sites, respectively).

\section{Non-permafrost sites}

- Burned non-permaforst sites also experience greater temperature extremes than the unburned sites, though much less so for the shallow organic zone $(4 \mathrm{~cm})$.

- Soil at the burned site continues to be dry out faster than soil at the unburned site. This difference is greatest for the shallow mineral zone $(15 \mathrm{~cm})$.

- The magnitude of these differences is smaller at these sites than for the sites with permafrost. 


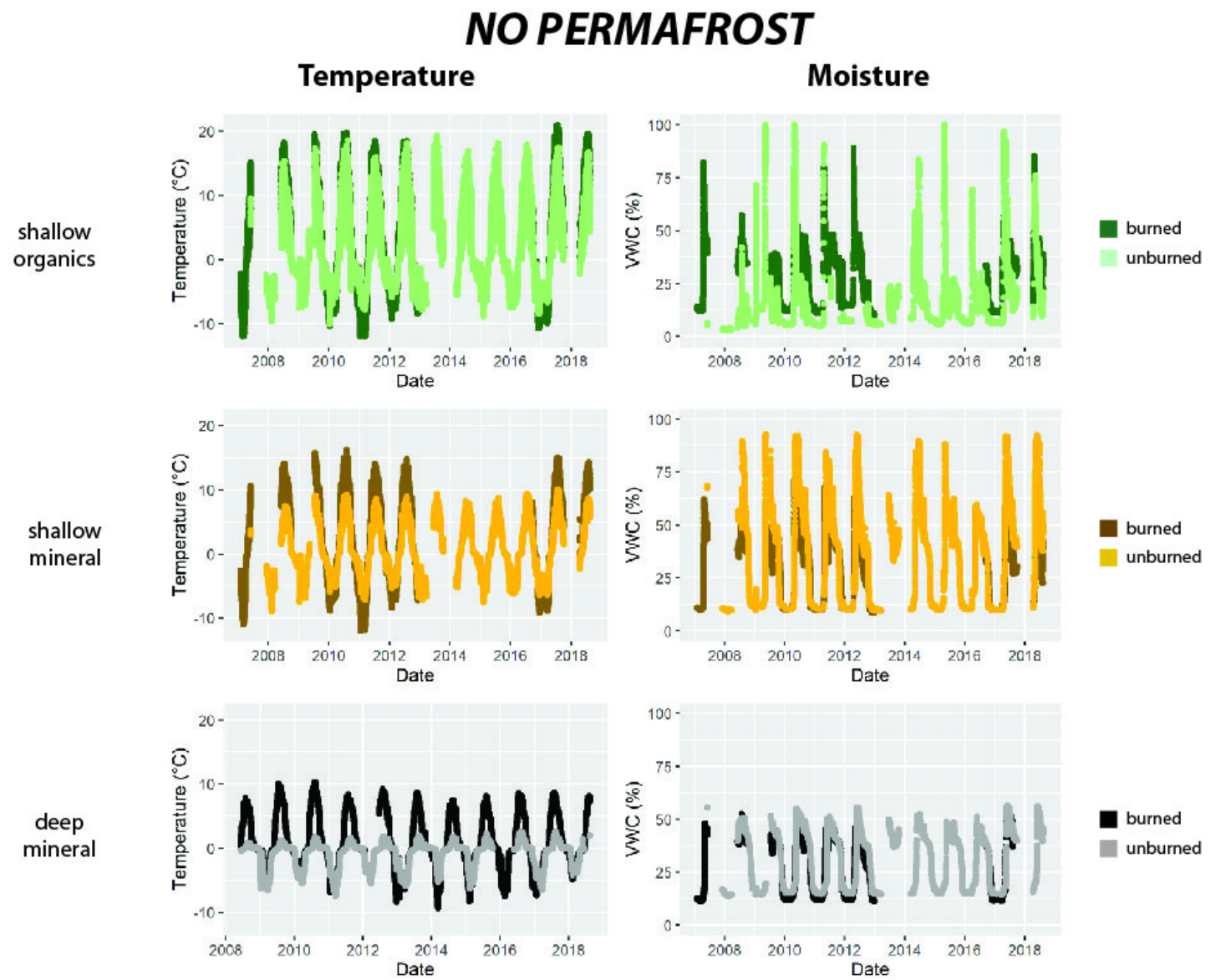

Figure 4. Soil temperature $\left({ }^{\circ} \mathrm{C}\right.$ ) and moisture (volumetric water content, or VWC, \%) from the soil pits without permafrost. Data are compared for different zones within this profile: surface organics $(4 \mathrm{~cm})$, shallow mineral soil $(15 \mathrm{~cm})$, and deeper mineral soil $(38 \mathrm{~cm})$. There is no deep organic zone at these sites because the organic soil of these sites are shallower than the permafrost site (Figure 3). 


\section{CHALLENGES}

There are many challenges in managing long-term sites and data, some being unique to the boreal region. These include:

1. Maintenance of the sites and data streams requires regular effort, which is often difficult to do over long time periods, especially if the sites are not located nearby. Irregular servicing and/or data analysis can lead to data gaps.

2. Soil organic matter continues to accumulate, so over time the depths of the instruments become inaccurate. In addition, these rates of accumulation differ between burned and unburned sites.

3. Long-term, more remote sites are more likely to be discovered by animals and people, sometimes resulting in destruction of instrumentation (see photos below).
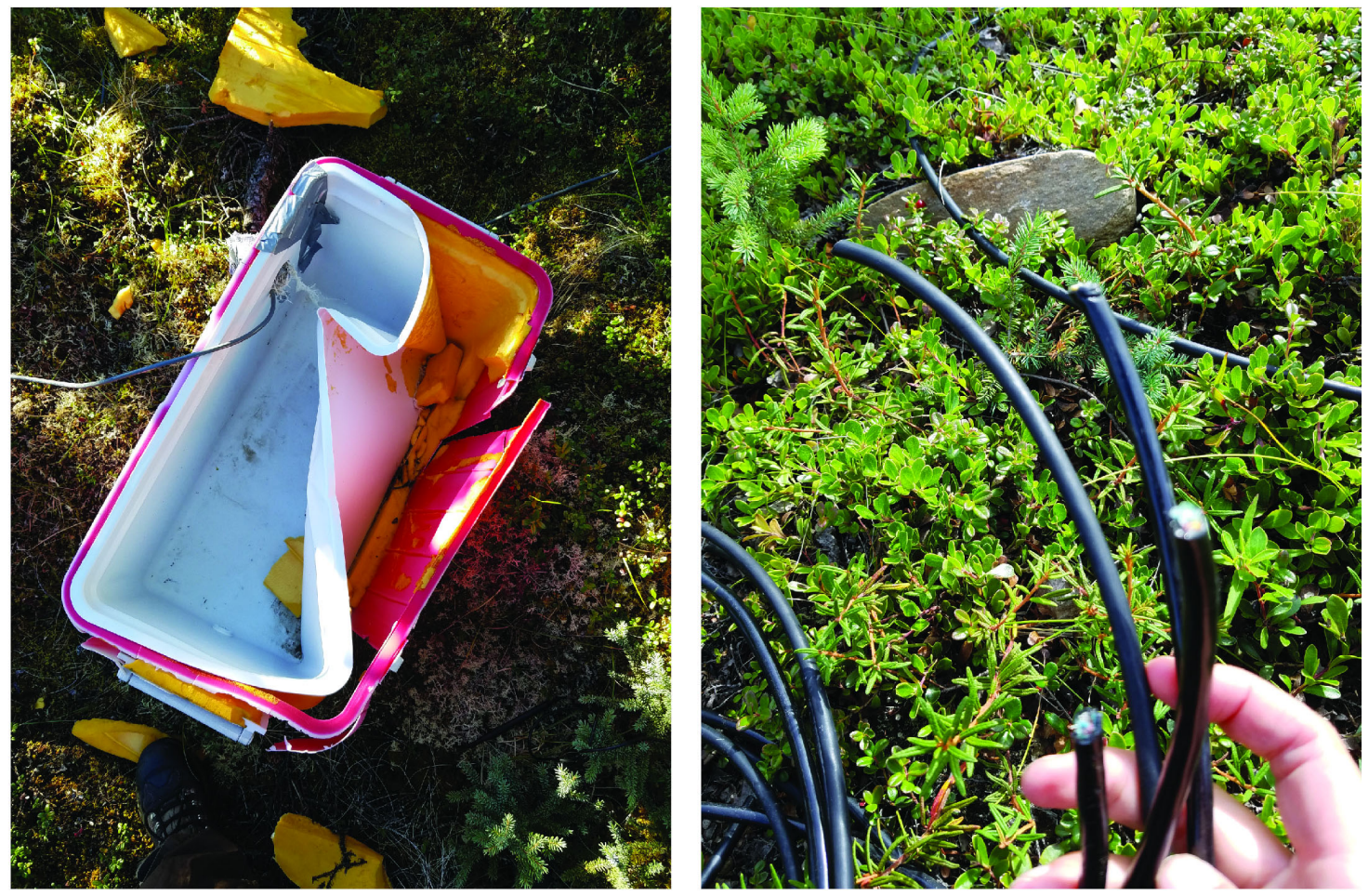

Figure 5 . Recent bear and human damage to our equipment. 


\section{CONCLUSIONS}

- Almost twenty years after fire there continue to be differences in soil temperature and soil moisture between burned and unburned sites.

- The magnitude of these differences changes depending on if the site does or does not have permafrost.

- Long-term data such as these are valuable for both model validation as well as providing insights into the effects of fire on soil temperature and moisture at various depths.

- Maintaining long-term soil measurements is challenging for a variety of reasons, including maintaining the time and personnel commitment, the burial of sensors with additional organic soil (which changes sensor depths over time), and the discovery of these instruments by animals and people.

- The data presented here are available from the Bonanza Creek Long-term Ecological Research Data Catalog by going to http://www.lter.uaf.edu/data/data-detail/id/765 (http://www.lter.uaf.edu/data/data-detail/id/765). 


\section{AUTHOR INFORMATION}

Kristen Manies; U..S Geological Survey (kmanies@usgs.gov)

Jennifer Harden, U..S Geological Survey (Emeritus)

Jamie Hollingsworth, Bonanza Creek Long-term Ecological Research Station

William Cable, Alfred Wegener Institute 


\section{ABSTRACT}

Wildfires are one of the main sources of disturbance in boreal forests. Post-fire changes to soil temperature and moisture regimes can have wide-ranging impacts on boreal forests including the depth at which permafrost is found, vegetation recovery, and carbon and nitrogen cycling. Surface soil temperatures increase following fire, due to loss of shading from tree canopies and a thinner surface organic layer. Post-fire soil temperature and moisture regimes also change due to reduced transpiration and changes in surface albedo. The duration of these changes depends on factors such as region, fire intensity, and soil texture. Here we present results from a long-term (1999 to present) dataset of soil conditions for four black spruce boreal forest sites located in Interior Alaska across burn and permafrost gradients: 1) burned, no permafrost, 2) unburned, no permafrost, 3) burned, with permafrost, and 4) unburned, with permafrost. The data from these sites demonstrate how both burning and the presence of permafrost influence soil temperature and moisture, as well as the timing of seasonal changes, for over twenty years. In addition, we discuss the challenges of maintaining and collecting data from field instruments deployed for decades in harsh conditions. All data discussed in this presentation will be available on the Bonanza Creek Long-term Ecological Research (LTER) website and is available for future studies. 


\section{REFERENCES}

Bourgeau-Chavez, L. L., et al. (2010). "Development of calibration algorithms for selected water content reflectrometry probes for burned and non-burned organic soils of Alaska." International Journal of Wildland Fire 19: 961-975.

Harden, J. W., et al. (2006). "Effects of wildfire and permafrost on soil organic matter and soil climate in Interior Alaska." Global Change Biology 12: 1-13.

Mack, M. C., et al. (2008). "Recovery of aboveground plant biomass and productivity after fire in mesic and dry black spruce forests of Interior Alaska." Ecosystems 11(2): 209

Manies, K., et al. (2020). "Generalized models to estimate carbon and nitrogen stocks of organic soil horizons in Interior Alaska." Earth Syst. Sci. Data 12(3): 1745-1757.

Randerson, J. T., et al. (2006). "The impact of boreal forest fire on climate warming." Science 314: 1130-1132. 